\title{
Educação do Campo e Autonomia: desenvolvimento comunitário e pedagogia de participação no Assentamento do Movimento Sem Terra [MST], Luís Inácio Lula da Silva (Lulão)
}

\author{
Altemar Felberg ${ }^{1}$, Geovani de Jesus Silva ${ }^{2}$ \\ ${ }^{1}$ Universidade Lusófona de Humanidades e Tecnologias - ULHT. Faculdade de Ciências Sociais, Educação e Administração. \\ Campo Grande, 276, 1749-024. Lisboa. Portugal. ${ }^{2}$ Universidade do Estado da Bahia - UNEB \\ Autor para correspondência/Author for correspondence: felberg_imt@hotmail.com
}

RESUMO. Este artigo busca apresentar o papel da Educação do Campo no processo de formação de sujeitos autônomos, a partir de estudo realizado em um assentamento do Movimento Sem Terra no Sul da Bahia, que buscou compreender de que modo os indicadores de desenvolvimento refletem o grau de autonomia de seus moradores. A investigação foi realizada por meio da pesquisa quali-quantitativa, tendo como instrumentos de coleta de informação o questionário, entrevistas semiestruturadas e grupos focais. Define-se aqui a autonomia como a capacidade do indivíduo governar-se, conforme uma lei própria, de maneira livre e racional, conduzindo-o à dignidade humana; configurando-se como um poderoso recurso capaz de livrar os indivíduos não só da submissão a processos heterônomos que interferem sobre suas liberdades de escolha e ação, mas também dos quadros de vulnerabilidade social e econômica. Ter mais autonomia e agir com maior liberdade de pensamento e ação melhora o potencial das pessoas para cuidar de si mesmas e para influenciar o mundo - questões centrais para o processo de desenvolvimento. Para potencializar a autonomia, a educação exerce um papel fundamental, no universo e na população estudada, efetivando-se na práxis da vida cotidiana, no exercício da cidadania e na participação social, consolidando-se como prática de liberdade.

Palavras-chave: Educação do Campo, Autonomia, Desenvolvimento Comunitário Rural. 


\title{
Rural Education and Autonomy: community development and pedagogy of participation in the Settlement of the Landless Movement [MST], Luís Inácio Lula da Silva (Lulão)
}

\begin{abstract}
This article seeks to present the role of Rural Education in the process of training autonomous subjects, based on a study carried out in a settlement of the Landless Movement in the South of Bahia, which sought to understand how development indicators reflect the degree Autonomy of its residents. The research was carried out through the qualitative research, with the questionnaire, semi-structured interviews and focus groups as instruments of information collection. Here autonomy is defined as the capacity of the individual to govern himself, according to a law of his own, in a free and rational way, leading him to human dignity; Setting itself up as a powerful resource capable of freeing individuals not only from submission to heteronymous processes that interfere with their freedoms of choice and action, but also from the frameworks of social and economic vulnerability. Having more autonomy and acting with greater freedom of thought and action improves people's potential to take care of themselves and to influence the world - issues central to the development process. To empower autonomy, education plays a fundamental role in the universe and in the population studied, taking place in the praxis of everyday life, in the exercise of citizenship and in social participation, consolidating itself as a practice of freedom.
\end{abstract}

Keywords: Rural Education, Autonomy, Rural Community Development. 


\section{Educación del Campo y Autonomía: desarrollo comunitario y pedagogía de participación en el Asentamiento del Movimiento Sin Tierra [MST], Luís Inácio Lula da Silva (Lulão)}

RESUMEN. Este artículo busca presentar el papel de la Educación del Campo en el proceso de formación de sujetos autónomos, a partir de un estudio realizado en un asentamiento del Movimiento Sin Tierra en el Sur de Bahía, que buscó comprender de qué modo los indicadores de desarrollo reflejan el grado De autonomía de sus habitantes. La investigación se realizó a través de la investigación cualitativa, teniendo como instrumentos de recolección de información el cuestionario, entrevistas semiestructuradas y grupos focales. Se define aquí la autonomía como la capacidad del individuo de gobernarse, conforme a una ley propia, de manera libre y racional, conduciéndolo a la dignidad humana; Configurándose como un poderoso recurso capaz de liberar a los individuos no sólo de la sumisión a procesos heterónomos que interfieren en sus libertades de elección y acción, sino también de los cuadros de vulnerabilidad social y económica. Tener más autonomía y actuar con mayor libertad de pensamiento y acción mejora el potencial de las personas para cuidar de sí mismas y para influir en el mundo - cuestiones centrales para el proceso de desarrollo. Para potenciar la autonomía, la educación desempeña un papel fundamental en el universo y en la población estudiada, que se efectúa en la praxis de la vida cotidiana, en el ejercicio de la ciudadanía y en la participación social, consolidándose como práctica de libertad.

Palabras clave: Educación del Campo, Autonomía, Desarrollo Comunitario Rural. 


\section{Introdução}

Buscamos, neste artigo, apresentar de que modo os indicadores de desenvolvimento comunitário rural do Assentamento do Movimento Sem Terra [MST], Luís Inácio Lula da Silva (Lulão), integrante da Brigada Elias Gonçalves de Meura, localizado no Extremo Sul da Bahia, refletem o grau de autonomia de seus moradores, homens e mulheres do campo, destacando, nessa relação, o papel da Educação do Campo no processo de formação de sujeitos com maior capacidade de reflexão crítica e ação, sobre si mesmos e o mundo.

Para obter os resultados expressos neste trabalho, adotamos a pesquisa qualiquantitativa, como enfoque metodológico, com a convergência das pesquisas descritiva e exploratória, tendo como instrumentos de coleta de informação, o questionário, entrevistas e grupos focais, aplicados a uma amostra de 30 pessoas, respeitando-se a divisão paritária e os critérios de gênero e geração, dentre os 57 associados/as originais do Assentamento.

Nessa jornada epistemológica, três importantes conceitos foram mobilizados para compreender a questão. Primeiro, a autonomia, entendida como a capacidade do indivíduo governar-se conforme uma lei própria, de maneira livre e racional, conduzindo-se à dignidade humana. Pode ser compreendida como um poderoso recurso capaz de livrar os indivíduos não só da submissão a processos heterônomos que interferem sobre suas liberdades de escolha e ação, mas também dos quadros de vulnerabilidade socioeconômica, devendo ser considerada como importante medida na avaliação do desenvolvimento, conforme os estudos de Kant (1974), Adorno (1984), Castoriadis (1991), Freire e Shor (1986), Chauí (1990), dentre outros. Segundo, a Educação do Campo, que conforme os estudos de Cury (2002), Arroyo, Caldart e Molina (2004) e Caldart (2009), surge como crítica à realidade do sistema educacional no Brasil, particularmente à situação educacional da população brasileira que trabalha e vive no/do campo, ao modelo de sistema econômico capitalista e sua injusta distribuição de renda, ao incentivo ao agronegócio e à expropriação de terras tradicionais, à elitização do acesso à ciência, à tecnologia, à cultura e às suas produções, enfim, críticas a não universalização de direitos que garantem uma maior cidadania. Terceiro, e último, o desenvolvimento comunitário rural, que se configura como um processo através do qual a comunidade amadurece em relação 
a si mesma, reconhece suas fragilidades e potenciais de desenvolvimento, rompe seus casulos e se transforma em novas possibilidades de ser (Silva \& Arns, 2002). Na visão de autores como Favareto (2006), Veiga (2005; 2006), Sen (2008), Sachs (2000), este tipo de desenvolvimento é identificado por meio de indicadores que ultrapassam o mero crescimento econômico, levando em consideração a avaliação de aspectos mais subjetivos, como acesso a oportunidades sociais, liberdades políticas e facilidades econômicas.

Assim, discutimos e analisamos os diversos aspectos que envolvem essas três categorias, estabelecendo as inúmeras possibilidades de relação entre elas, no universo e sujeitos estudados, buscando compreender o desenvolvimento e exercício da autonomia, a partir dos contributos da Educação do Campo, rumo ao 'desenvolvimento com autonomia'.

\section{Autonomia: uma condição do sujeito de "ser para si"}

Em revisão literária, podemos perceber que o conceito de autonomia que etimologicamente vem do grego autós (ele mesmo, por si mesmo) e nomos (lei, convenção, regra), que significa o poder de dar a si a própria lei - fora construído historicamente pelas diferentes características culturais, econômicas e políticas que configuraram as sociedades ao longo de sua trajetória, tendo sido refletido inicialmente pelos historiadores e filósofos gregos e ganhado destaque e notoriedade na modernidade com os estudos de Kant (1974).

Posteriormente aos estudos kantianos, diversos outros autores se debruçaram sobre a temática, abordando a autonomia numa perspectiva mais política e sociológica, a partir de um entendimento de que os conceitos de autonomia e participação social possuem tênue relação. Adorno (1984), Freire e Shor (1986), Chauí (1990), Castoriadis (1991), Bobbio (2000) e Sen (2008) são apenas alguns destes autores, dentre muitos outros.

Para Castoriadis (1991), a autonomia conduz diretamente ao problema político e social da humanidade, posto que não se pode desejá-la sem desejá-la a todos, e cuja realização só pode conceber-se plenamente como empreitada coletiva. Esse entendimento é também defendido por Freire e Shor (1986) quando nos alertam de que mesmo quando nos sentimos mais livres, mais autônomos, se esta conquista não for utilizada a favor da coletividade, estaremos apenas exercitando uma 
autonomia individualista, no sentido do empoderamento pessoal.

Nesta mesma linha, Chauí (1990) nos diz que a autonomia é a posição do sujeito sócio-histórico-cultural que, por sua própria ação e vontade ética, é criador das leis e regras da sua existência social e política; o que na perspectiva freiriana tem a ver com o 'ser para si', onde num contexto histórico subdesenvolvido dos oprimidos, a autonomia está intimamente relacionada com a libertação. É justamente sob esta perspectiva que se pretende firmar este texto, reconhecendo a autonomia como defende Pereira (2007), como um recurso capaz de livrar os indivíduos não só da heteronomia de processos opressores sobre as suas liberdades de escolha e de ação, mas também da miséria e do desamparo, da privação do exercício de um dos direitos sociais mais sagrados: a participação ativa e qualificada nos processos de discussão, formulação e usufruto efetivos das políticas de desenvolvimento.

O conceito de autonomia advém do sentido de participação política e social, a qual é considerada como um das mais importantes medidas na avaliação do desenvolvimento “...a liberdade de participação ou dissensão política ou as oportunidades de receber educação básica, são ou não são conducentes ao desenvolvimento" (Sen, 2008, p. 19), ideia corroborada também por Frey (2000), o qual defende que autonomia apresenta-se como dimensão a ser considerada, seja nos indicadores, seja no ciclo das políticas públicas.

Para os autores, ter mais autonomia e agir com maior liberdade de pensamento e ação, melhora o potencial das pessoas para cuidar de si mesmas e para influenciar o mundo - questões centrais para o processo de desenvolvimento. E como conquistar ou potencializar essa autonomia? Aí entra o papel da educação, seja formal ou informal.

$\mathrm{Na}$ sua obra sobre pedagogia, Kant (1996) fala sobre a importância de a ação educativa seguir a experiência. A educação não deve ser puramente mecânica e nem se fundar no raciocínio puro, mas deve apoiar-se em princípios e guiar-se pela experiência. A partir da pedagogia kantiana, podemos dizer que uma educação que vise formar sujeitos autônomos deve unir lições da experiência e os projetos da razão.

Neste sentido, a temática da autonomia, que ganhou centralidade nos pensadores e na educação moderna, especialmente em Freire e Shor (1986) que a atribui um sentido sócio-político- 
pedagógico: autonomia é a condição sóciohistórica de um povo ou pessoa que tenha se libertado, se emancipado das opressões que restringem ou anulam sua liberdade de determinação. E conquistar a própria autonomia implica, para Freire e Shor (1986), em libertação das estruturas opressoras - uma das bandeiras defendidas pelos educadores e educadoras da Educação do Campo.

Não é preciso estar no dia a dia das populações que vivem no/do campo para notar o quadro de marginalidade $\mathrm{e}$ exclusão em que se encontram, seja na esfera nacional ou local, delineado a nosso ver, principalmente, dentre outros fatores, pela ineficácia das políticas públicas, principalmente no que tange ao oferecimento de uma educação de qualidade e libertária da dependência e alienação - base primordial para a conquista do poder, em suas várias dimensões, capaz de promover e transformar a sociedade. Um poder, no sentido usado por Freire e Shor (1986), como um aumento da conscientização e desenvolvimento de uma "faculdade crítica"; um poder de "fazer" e de "ser capaz", bem como de sentir-se com mais capacidade para agir e desempenhar um papel ativo nas iniciativas de desenvolvimento.
Nesse contexto, há perspectivas que apontam que a restrição da autonomia dos atores sociais do meio rural elidem as possibilidades desses grupos menos favorecidos em participar ativamente dos processos de discussão, formulação e usufruto efetivos de políticas de desenvolvimento local. Por outro lado, a autonomia construída a partir da expansão das capacidades individuais e coletivas, de refletir e decidir autonomamente sobre aquilo que é significativo e de valor para si e para seu grupo, pode ampliar as possibilidades de exercício da cidadania, de luta contra as pressões externas e de desenvolvimento.

\section{Sentido da autonomia para moradores do Assentamento Lulão}

O Assentamento Luiz Inácio Lula da Silva (Lulão), antiga Fazenda Coroa Cabrália, com área total aproximada de 650 hectares, está localizado no Município de Santa Cruz Cabrália, Costa do Descobrimento, Extremo Sul da Bahia, na altura do $\mathrm{Km} \mathrm{22}$, às margens da rodovia BR 367, a 167m de altura, com latitude de 1638328135 e longitude de 39.38086867 , encontrando-se a $46 \mathrm{~km}$ de Porto Seguro (BR 367), 03 km de Vera Cruz (BR 367) e $23 \mathrm{~km}$ de Eunápolis. 
Atualmente, possui 57 famílias $\operatorname{assentadas}^{\mathrm{i}}$ e uma população estimada em 228 habitantes, que vivem sob um sistema de moradia organizado em Agrovila, possuindo, cada assentado, uma área de produção individual de 5,00 hectares $(3,4$ de terra livre e 1,6 de reserva legal) e a possibilidade de participação em atividades coletivas de produção.

Inicialmente, era conhecido como Projeto de Assentamento Coroa de Cabrália, fruto de um processo de luta do MST, que teve início em meados de 2002, a partir da chegada à região, do militante Francisco de Assis Souza, conhecido como "Estrela". Naquela época, o espaço onde hoje é o Assentamento era uma área improdutiva e desabitada, com uma grande descrença em relação à conquista da terra, como descreve um dos assentados entrevistados:

Eu lembro. No início aqui era uma fazenda, uma fazenda, é... cheia de mato; eu morava aqui ao lado, na cidade de Vera Cruz, aqui perto, aí o pessoal acampou botando barraco de lona e tudo, a minha mãe mesmo foi uma delas...Aí eu falei assim: "Meu Deus do céu, minha mãe, a senhora tá doida, ficar nesse lugar aqui?" (++) um deserto, não tinha ninguém, o pessoal estava fazendo casa ... dormindo debaixo das lonas, com medo de sumir os material (Indaiá, excerto extraído do Grupo Focal $n^{\circ}$ 02, realizado em maio de 2016, p. 1).
Mesmo encontrando dificuldades no processo de articulação e mobilização de famílias para inserção na luta pela terra na região, "Estrela" surpreendeu, ao reunir mais de 1.500 pessoas para a ação de ocupação de terra em área próxima ao entroncamento de Trancoso, em Porto Seguro, às margens da BR 367. Pela conjuntura política e dimensão da ação, o acampamento recebeu o nome de Luís Inácio Lula da Silva, apelidado depois de "Lulão".

As famílias que hoje se encontram assentadas no Assentamento "Lulão" participaram e são oriundas de inúmeros acampamentos do MST, espalhados pela região do Extremo Sul da Bahia, de acordo com os relatos abaixo:

... aí um dia passa uma pessoa em minha casa e falou: "Você não quer participar, pegar essas famílias e participar do MST?" Ia ter a ocupação do Chico Mendes (++). Aí eu falei: "Vou pensar". Depois eu falei não. Vou nada, não vou, porque é muita bagunça, muita briga, e eu não vou pegar essas famílias, né, e levar pra isso, que a gente estava tentando, naquela ilusão de que conseguiria as coisas, tudo numa boa, né? ... eu conheci o acampamento do MST, e aí surgiu o interesse, também pelo fato de entrar no acampamento, ver a organização né, ver ali aquelas famílias já produzindo né, então eu resolvi ir para esse acampamento do MST, em Guaratinga, que era Itatiaia, e lá a gente começou a nossa história no movimento ... (Areca,

\begin{tabular}{|l|l|l|l|l|l|l|l|}
\hline Rev. Bras. Educ. Camp. & Tocantinópolis & v. 3 & n. 2 & p. 381-410 & mai./ago. & 2018 & ISSN: 2525-4863 \\
\hline
\end{tabular} 
excerto extraído do Grupo Focal $n^{\circ}$ 01, realizado em maio de 2016, p. 1).

... eu fui pra lá em 1998, e aí permaneci lá até 2003, na Rosinha do Prado. Rosinha do Prado é tudo, até hoje, em qualquer canto. Foi a minha escola. Ali, conversei com eles, foi o momento que eles colocaram que o município de Porto tava montando um acampamento, que estaria surgindo um acampamento em Eunápolis, se eu poderia ajudar. Eu coloquei pra eles que eu iria pensar, mas que realmente, pra mim, era uma alegria que eu estava dentro da organização, mas não fui logo, aí foi assim que surgiu o Salgado. E aí, dali do Salgado, em 2005, nós acabamos vindo pra aqui. (Aricuri, excerto extraído do Grupo Focal $\mathrm{n}^{\circ}$ 01, realizado em maio de 2016, p. 2-3).

Quando nós chegou aqui, já tinha uma quantidade de pessoas né, já... né, de outro local, que era do Lulão, que a gente veio do Salgado, né, perto de Eunápolis, próximo à Eunápolis. Quando a gente veio pra aqui, começou a conhecer, né, esses outros barracos, né, fomos conviver com as pessoas que a gente não conhecia ainda. (Babaçu, excerto extraído do Grupo Focal $\mathrm{n}^{\circ}$ 02, realizado em maio de 2016, p. 1).

Os três depoimentos demonstram características peculiares dos sujeitos semterra: primeiro, de serem forjados e formados no movimento, na luta pela terra, por direitos e por melhores condições de vida; segundo, pelo aparente sentimento de pertencimento a um grupo social; e terceiro, pela solidariedade e coesão social demonstrada nos processos de construção e desenvolvimento dos acampamentos semterra.

Em abril de 2004, a ocupação foi estendida às terras de uma multinacional de celulose, que ficavam ao lado do acampamento "Lulão", ação que forçou o Governo Federal a negociar três áreas para assentar as famílias: Fazenda Serro Azul, situada no Município de Porto Seguro, hoje Assentamento Milton Santos; Fazenda Bela Vista Movelar, situada no Município de Cabrália, hoje Assentamento Ojeferson Santos; e a Fazenda Coroa de Cabrália, situada no Município de Santa Cruz Cabrália, hoje Assentamento Luís Inácio Lula da Silva.

Fato histórico e de muito orgulho para os sem-terra do Acampamento Lulão ocorreu no dia 20 de janeiro de 2005, quando o então Presidente da República, Luis Inácio Lula da Silva, visitou o acampamento e reafirmou a luta do seu governo para a consolidação da Reforma Agrária no país, comprometendo-se com as famílias presentes a assentar todas elas ainda naquele ano, e participar da entrega oficial da emissão de posse das áreas.

Conforme o prometido, em 22 de setembro de 2005 chegou a notícia, pelas mãos de dirigentes do Instituto Nacional de Colonização e Reforma Agrária [INCRA], do Governo do Estado da Bahia e de 
líderes do MST, que as terras reivindicadas pelas famílias estavam liberadas para o processo de Assentamento, o que foi motivo de grande comemoração e alegria, segundo relata Santos (2015).

Assim, imediatamente à confirmação da tão esperada notícia, as famílias seguiram para as três áreas recentemente conquistadas, dando origem aos Assentamentos Milton Santos, Ojeferson Santos e Luís Inácio Lula da Silva. Esse acontecimento é narrado por Macaúba:

... aí depois foi quando saiu pra cada um o pedaço de terra, aí cada um foi mudando pros seus lugares, só que ainda não era o local certo, aí minha mãe ficou logo em uma terrinha aqui próxima, e aí nós ia pra lá, e aí todo mundo ficou mudando. Uns ficou aqui, outros foram mudando pras terrinhas, aí depois que teve o local certo, que dividiu os lotes e cada um foi pros seus lotes, aí cada um foi se virar e fazer o seu. (Macaúba, excerto extraído do Grupo Focal $\mathrm{n}^{\mathrm{o}}$ 02, realizado em maio de 2016, p. 1).

Depois de devidamente assentadas, com moradias em regime de Agrovilas, lotes individuais e áreas coletivas de produção, o então Presidente Luís Inácio Lula da Silva reúne-se, no dia 27 de setembro de 2005, com todas as famílias, para entregar oficialmente a imissão de posse das áreas. O presidente abre seu discurso, dizendo:
$\mathrm{Eu}$ queria chamar aqui o seu Tertuliano, se ele pode ficar aqui do lado, porque eu acho que a nossa querida Anita Maria de Jesus e o nosso querido Tertuliano Dias Nascimento, ela com 64 anos de idade, e ele com 82 anos de idade, são a mais viva demonstração... E eu vou repetir uma coisa que eu dizia em 89 , em 94, em 98, e não posso mudar o meu discurso porque eu virei Presidente da República. Eu sempre achei que a grande coisa, ou uma das grandes coisas que o Movimento Sem-Terra faz, pelo Brasil, é que o Movimento SemTerra é capaz de tirar pessoas que estão quase virando párias da sociedade, espalhadas por esse mundo, sem esperança, e transformálas em guerreiros e guerreiras, como ele fez com a Dona Anita ou com o senhor Tertuliano: dar esperança, perspectiva, mostrar um horizonte para as pessoas, o que só acontecerá com muita perseverança e com muita luta (Brasil, 2005, p. 1-2).

Em seu discurso, o presidente fala da árdua luta dos trabalhadores e trabalhadoras rurais sem-terra, e reconhece a importante contribuição do MST para a construção de um país mais justo, fraterno e humano, com igualdade de oportunidades a todo brasileiro.

Considerando o potencial de desenvolvimento da terra conquistada, a aprendizagem social oportunizada por meio da participação no MST e a luta e esforço dos sem-terra no Assentamento "Lulão", dez (10) anos depois da sua criação, é que tratamos de compreender de que modo os indicadores de 
desenvolvimento comunitário rural desse assentamento refletem o grau de autonomia de seus moradores e qual o papel da educação no processo de formação de sujeitos autônomos.

A partir do entendimento de que a autonomia pode ser definida como a capacidade de conceber e fazer suas próprias escolhas, tratando-se de uma condição a ser conquistada individualmente pela independência da vontade e pela liberdade de ação, apresentamos, a seguir, o sentido dessa autonomia para os homens e as mulheres trabalhadores/as rurais sem-terra, sujeitos da pesquisa realizada no Assentamento "Lulão".

No universo pesquisado percebe-se que a autonomia individual das mulheres traduzida na capacidade destas, de conceber e fazer suas próprias escolhas - é bastante significativa, registrando-se uma alta porcentagem, entre $86,67 \%$ e $100 \%$, que demonstram decidir autonomamente sobre questões do âmbito da vida privada, considerando-se o representado nas questões que tratam da liberdade e poder de decisão de ir e vir, de levar a vida conforme seus próprios preceitos, de realizar trabalhos domésticos por vontade própria, de como se vestir, de visitar amigos quando sente vontade, de como utilizar o tempo livre e de relaxar quando sente vontade. Todavia, se analisarmos as questões que se relacionam à vida coletiva, notaremos que esta capacidade de pensar e agir autonomamente sofre interferência, especialmente no que se refere à externalização de ideias, opiniões e emoções.

Vale destacar que $53,33 \%$ descartam a possibilidade de respeitarem ou seguirem somente as regras que julgam necessárias, o que confirma a tese defendida por Morin (2002), quando este afirma que a autonomia não se trata de uma liberdade total e plena, livre de qualquer dependência e influência externa, mas uma autonomia que depende de seu meio ambiente; o que é visivelmente representado no seguinte relato de uma das assentadas:

... aqui tem uma regra, mas você
escolhe, você é livre, ninguém vai
impedir o que você vai fazer, só que
aí você tem que respeitar as normas
do movimento, e eu creio assim: se
você quer fazer algo, não querer
respeitar as normas daquele
assentamento, se acontecer algo com
você ou alguma coisa, a direção não
tem nada a ver, porque você que
escolheu a sua escolha, então você
tem livre arbítrio pra fazer o que você
quiser, só que tem que fazer o certo
pra você poder ter o reconhecimento
aqui dentro e poder desfrutar do que
tem aqui no assentamento, porque
tem muita coisa boa, agora basta
você querer (Macaúba, excerto
extraído do Grupo Focal no 02 ,
realizado em maio de 2016).

\begin{tabular}{|l|l|l|l|l|l|l|l|}
\hline Rev. Bras. Educ. Camp. & Tocantinópolis & v. 3 & n. 2 & p. 381-410 & mai./ago. & 2018 & ISSN: 2525-4863 \\
\hline
\end{tabular} 
O fato de o sujeito decidir abdicar de sua autonomia individual, a favor do bemestar coletivo, não significa que o mesmo perdeu sua capacidade intelectual de conceber e fazer suas próprias escolhas, como bem explica Morin (2002), pois a pessoa dotada de liberdade, sem intervenção alheia, torna-se autônoma à medida que utiliza a liberdade com maior clareza e consciência em suas atitudes na sociedade, de acordo Kant (1974), uma vez que, no estado civil, o homem adquire uma liberdade moral, já que ele passa a obedecer a uma lei que ele instituiu a si próprio, em vez de seguir o impulso, conforme Rousseau (1978).

Fazendo uma análise comparativa entre a autonomia para as mulheres e a autonomia para os homens, podemos inferir que a autonomia individual dos homens é bastante similar à das mulheres, com registro de alta porcentagem de autonomia (entre $86,67 \%$ e $100 \%$ ) para as questões relacionadas à vida privada, já explicitadas na análise anterior, com exceção aqui para a questão relacionada à liberdade de ir e vir, onde $33,33 \%$ dos homens disseram nunca sair sem autorização, e a questão relacionada à decisão de como gastar/investir a renda familiar, onde $26,67 \%$ afirmaram sentir a necessidade de dividir a decisão com a companheira, o que pode aqui ser justificado pelo fato de serem casados e culturalmente compartilharem as decisões da vida cotidiana com as mulheres, que no universo e população estudados, tem grande poder de decisão, conforme relatos abaixo:
A minha história veio através da minha esposa, eu não gostava do movimento, eu tinha uma imagem que o movimento era (++) não era boa a imagem do movimento. Minha esposa, ela tem alguns parentes na liderança do movimento há vinte e cinco (25), trinta (30) anos... eu comecei a namorar com ela e ela me convidava pra eu visitar, e eu falava: "eu não, você vai só, eu não vou não" (Buriti, excerto extraído do Grupo Focal $\mathrm{n}^{\circ} 01$, realizado em maio de 2016, p. 1).

No relato acima é retratada a influência da mulher nas decisões da vida privada, mas, sobretudo, seu papel nos processos de mobilização social e representação do MST, conquistando sua autonomia a partir de uma atuação efetiva no movimento.

Já no que diz respeito às demais questões que se relacionam à vida coletiva, à capacidade de pensar e agir conforme sua própria razão e vontade, percebe-se uma interferência, especialmente no que se refere à externalização de ideias, opiniões e emoções. 53,33\% descartam a possibilidade de respeitarem ou seguirem 
somente as regras que julgam necessárias, comportamento já, outrora, explicado por Rousseau (1978), Kant (1974) e Morin (2002), que existe um consenso de que a vontade individual cede lugar à vontade coletiva.

Por fim, a pesquisa também revela que uma das estratégias para o desenvolvimento e sua avaliação é a importância e valorização da participação e da autonomia dos indivíduos, transformando-os em sujeitos de ação, o que pode ser entendido como a busca de um maior grau de conscientização e interferência no processo de dinamização socioeconômica e cultural da localidade, através da ação coletiva e organizada.

\section{Educação do/no Campo: construção de uma pedagogia do movimento}

Essa história é muito bem contada pelos estudiosos e militantes da área, Miguel Arroyo, Roseli Caldart e Mônica Molina (2004), dando voz e repercutindo o desejo de um grupo que brada um pedido de respeito a uma população historicamente marginalizada; um manifesto por uma educação não periférica à das cidades, que considere a singularidade do modo de vida do homem e mulher do campo; que considere sua história, valores, cultura e identidade e; que desmistifique o campo como lugar atrasado, obsoleto e fadado à extinção.

Essa retrospectiva começa com a luta dos movimentos sociais e dos educadores e educadoras do campo pelo direito à educação, assim como à reforma agrária. Direito esse que foi negado e usurpado à população brasileira do campo há décadas, com raízes que remontam o processo de colonização da nação brasileira, como salienta Batista (2011, p. 54-55):

\begin{abstract}
As lutas no campo brasileiro têm início com o processo de invasão e colonização portuguesa. Os movimentos se originam dos conflitos em torno da luta por terra, mas também se rebelam contra as relações sociais de produção marcadas pela exploração, pela dominação e degradação da pessoa humana, como a escravidão, contra a negação da cidadania, pelos direitos sociais e trabalhistas, pelo reconhecimento das diferentes culturas. Essas múltiplas demandas envolveram diferentes sujeitos, índios, negros, caboclos, agricultores, escravos, ferreiros, barqueiros. O que denota que a resistência dos povos oprimidos e despossuídos esteve presente ao longo da história brasileira, nos períodos colonial, monárquico e republicano e é um dos elementos da identidade política do povo.
\end{abstract}

Nos séculos seguintes à colonização, até meados do início do século XIX, ainda segundo a autora, é fato que diversas mudanças socioeconômicas e culturais ocorreram - sobretudo por força dos 
processos de resistências - sem, contudo, provocarem transformações sociais efetivas e duradouras, especialmente no campo da educação, prevalecendo o método pedagógico jesuítico do período colonial, que se estendeu de 1549 a 1759 , ressoando nas décadas seguintes até a independência. Com essa ruptura, daí em diante, algumas iniciativas relativas à educação foram efetivadas, contudo, apesar dos avanços na área, ainda não se tinha um sistema educacional de âmbito nacional, o que só se concretizou no século XX.

Em relação à Educação do Campo, os militantes e profissionais "por uma educação diferenciada do campo" declaram que apesar dos movimentos docente e pedagógico progressista do Brasil buscarem o reconhecimento da educação como um direito humano desde a década de 80, as conquistas alcançadas pelo movimento não geraram os frutos esperados no campo. Argumentam que o direito à educação então conquistado pelo movimento progressista "ficou vinculado a uma concepção abstrata de cidadania, não traduzindo a concretude humana e social em que os direitos se tornam realidade" (Arroyo, Caldart \& Molina, 2004, p. 10). Tal concepção reafirmava o discurso elitista da época, ao considerar cidadãos somente os habitantes da cidade.

Diante desse contexto, fica clara, então, na percepção aguçada dos autores citados, em especial na releitura do assunto por Roseli Caldart (2009), que a Educação do Campo nasceu, essencialmente, como crítica à realidade do sistema educacional no Brasil, particularmente à situação educacional da população brasileira que trabalha e vive no/do campo. Uma crítica não apenas à educação, mas ao modelo de sistema econômico capitalista e sua injusta distribuição de renda; ao incentivo ao agronegócio e a expropriação de terras tradicionais; à elitização do acesso à ciência, à tecnologia, à cultura e às suas produções; enfim, críticas a não universalização de direitos que garantem a plena cidadania.

Dessa forma, a crítica, ainda na visão da autora, não foi voltada exclusivamente à educação escolar em si, mas como essa educação estava desalinhada à realidade educacional do país, que não considerava a especificidade dos processos sociais, políticos e culturais pujantes do campo, processos estes que extrapolavam sobremaneira as discussões para além de uma educação linear, cartesiana e formadora de indivíduos na ótica do capitalismo; e ainda, como essa educação 
desconsiderava a totalidade do sujeito, sua natureza e condição de agente sóciohistórico-cultural, ou seja, "precisamos considerar na análise que há uma perspectiva de totalidade na constituição originária da Educação do Campo" (Caldart, 2009, p. 38). Vale destacar que a crítica não se deu no campo da epistemologia da educação (ainda que isso ocorresse naturamente por consequência do processo), pelo contrário, foi fundamentada numa "crítica prática", forjada no calor das reivindicações dos movimentos sociais, que lutavam pelo direito à educação a partir da "realidade da luta pela terra, pelo trabalho, pela igualdade social, por condições de uma vida digna de seres humanos no lugar em que ela aconteça" (Caldart, 2009, p. 39). Tratou-se, então, de

uma crítica prática que se fez teórica ou se constituiu também como confronto de ideias, de concepções, quando pelo 'batismo' (nome) assumiu o contraponto: Educação do Campo não é Educação rural, com todas as implicações e desdobramentos disso em relação a paradigmas que não dizem respeito e nem se definem somente no âmbito da educação. (Caldart, 2009, p. 40).

Retornando à sua origem, sabida e reconhecidamente, os grandes protagonistas do processo de criação da Educação do Campo e seu aperfeiçoamento foram os "movimentos sociais camponeses em estado de luta" (Caldart, 2009, p. 40), com destaque aos movimentos sociais de luta pela reforma agrária, particularmente ao MST.

No decorrer da luta, outros movimentos sociais em defesa do povo campesino foram surgindo e aderindo à causa por uma Educação do Campo, consolidando-a como hoje a conhecemos: o Movimento dos Atingidos por Barragens [MAB], o Movimento das Mulheres Camponesas [MMC], o Movimento dos Pequenos Agricultores [MPA], a Pastoral da Juventude Rural [PJR], a Comissão Pastoral da Terra [CPT] e a Federação dos Estudantes de Agronomia [FEAB]. Somaram-se às iniciativas o movimento sindical do campo, especialmente àqueles vinculados à Confederação Nacional dos Trabalhadores na Agricultura [CONTAG] e à Federação dos Trabalhadores na Agricultura Familiar [FETRAF]. Assim,

o vínculo de origem da Educação do Campo é com os trabalhadores 'pobres do campo', trabalhadores sem-terra, sem trabalho, mas primeiro com aqueles já dispostos a reagir, a lutar, a se organizar contra 'o estado da coisa', para aos poucos buscar ampliar o olhar para o conjunto dos trabalhadores do campo. (Caldart, 2009, p. 41).

Para a autora, talvez seja essa a marca histórica mais incômoda e

\begin{tabular}{|l|l|l|l|l|l|l|l|}
\hline Rev. Bras. Educ. Camp. & Tocantinópolis & v. 3 & n. 2 & p. 381-410 & mai./ago. & 2018 & ISSN: 2525-4863 \\
\hline
\end{tabular} 
fascinante da Educação do Campo no contexto sócio-histórico-políticoeconômico e cultural do país: o protagonismo e a autonomia dos sujeitos que vivem do/no campo. Hoje, por todo país,

milhares de educadoras e educadoras se mobilizam, se reúnem, debatem, estudam e refazem concepções e práticas educativas em escolas de comunidade camponesas, em escolas-família agrícola, em escolas dos reassentamentos do Movimento dos Atingidos pelas Barragens, em escolas de assentamentos e de acampamentos do Movimento dos Sem Terra, ou em escolas de comunidades indígenas e quilombolas. (Arroyo, Caldart \& Molina, 2004, p. 09).

Assim, diante o exposto, fica evidente que a Educação do Campo surgiu em um determinado momento e contexto histórico brasileiro que não pode ser compreendida e analisada em si mesma, segundo afirma Caldart (2009), tomando unicamente por base os "parâmetros teóricos da pedagogia”. Ela extrapola o campo da ciência da educação e provoca reflexões em várias outras áreas, como a política, a sociologia e a economia; gerando discussões no intuito de romper velhos paradigmas e propor novos caminhos para um desenvolvimento mais ético, justo e igualitário.
Educação como prática da liberdade: contributos da Educação do Campo para construção da autonomia de homens e mulheres do campo

Exposto em que contexto a Educação do Campo surgiu e se desenvolveu (a Educação do Campo como crítica ao sistema e como resultado da luta de classes, protagonizada pelos atores sociais que reivindicavam a educação como um direito), partamos agora para outra frente de compreensão do fenômeno, a Educação do Campo como práxis pedagógica, como princípio e fundamento da luta e das conquistas dos trabalhadores e trabalhadoras.

Preliminarmente à apresentação dessa outra frente de entendimento da Educação do Campo enquanto fenômeno não apenas educativo, mas social, cabe aqui destacar a realização e os resultados das discussões e consensos da I Conferência Nacional "Por uma Educação Básica do Campo", realizada em Luziânia, Goiás, entre 27 a 31 de julho de 1998, evento que é considerado o "batismo coletivo" de toda uma luta pelo direito à educação, na qual, foram discutidas e analisadas várias demandas, dentre elas: a) o tipo de educação que estava sendo ofertada no campo era contrária à proposta de educação proposta pelo movimento,

\begin{tabular}{|l|l|l|l|l|l|l|l|}
\hline Rev. Bras. Educ. Camp. & Tocantinópolis & v. 3 & n. 2 & p. 381-410 & mai./ago. & 2018 & ISSN: 2525-4863 \\
\hline
\end{tabular} 
uma educação mais ampla, voltada à formação humana do sujeito; b) revisão do que se entende por educação básica e escolarização, resultando na formulação de uma proposta de escola do campo, que considere experiências exitosas e significativas de educação não formal e de caráter popular; c) a substituição do termo "meio rural" por "campo", a fim de trazer ao termo a essência do conceito de camponês, que representa a diversidade de sujeitos que vivem do/no campo e; d) a construção de pilares metodológicos para uma educação básica do campo, que representasse seu caráter diferenciado, assumindo a identidade do meio rural e voltada a um projeto nacional de desenvolvimento do campo brasileiro.

Não podemos perder de vista a riqueza das experiências e aprendizagens adquiridas por Miguel Arroyo (2004) quando da sua participação no $1^{\circ}$ Encontro de Educadores dos Assentamentos de Belo Horizonte, em 1994, e na $1^{\text {a }}$ Conferência Nacional "Por uma Educação Básica do Campo", em 1998, o que ele chama de pedagogia dos gestos, pedagogia do fazer, expressando as muitas formas de expressão e linguagens utilizadas pelos educadores e membros dos movimentos sociais do campo, que a todo o momento, formam e educam para a cidadania, uma nova concepção de escola. A grande reflexão e contribuição trazida pelos documentos resultantes desses encontros é o 'movimento social como princípio educativo' e como ferramenta de luta por direitos. Para o Miguel Arroyo (2004) “o movimento social no campo representa uma nova consciência do direito a terra, ao trabalho, à justiça, à igualdade, ao conhecimento, à cultura, à saúde e à educação" (p. 73).

No início dos anos 2000, Roseli Caldart escreveu o documento intitulado “A Escola do Campo em Movimento", o qual retrata a experiência particular das escolas do MST e sua proposta pedagógica de formação para a autonomia, a partir da dinâmica das lutas pela implementação de um projeto de desenvolvimento do campo. O texto carrega em si três importantes argumentos e pontos de reflexão: o primeiro, de que o campo no Brasil encontra-se em constante movimento e processo de mudança social; o segundo, de que a Educação do Campo está sendo construída na dinâmica social desse processo desenvolvimentista, sendo retroalimentada a todo instante pelos atores sociais que dela participam e; terceiro, de que é dinâmico o processo de humanização no campo a partir da educação e da assunção dos sujeitos enquanto sujeitos 
sócio-histórico-culturais, agentes de transformação, protagonistas de suas próprias histórias de desenvolvimento, pessoal e social.

Em seguida, Bernardo Fernandes redige as "Diretrizes de uma Caminhada", documento que se configura como uma grande conquista do Movimento "Por uma Educação do Campo" iniciado em 1998, trazendo uma análise dos significados da aprovação, pelo Conselho Nacional de Educação, das Diretrizes Operacionais para a Educação Básica nas Escolas do Campo. O texto faz menção a uma caminhada que se iniciou em 1997 quando da realização do Encontro Nacional de Educadores e Educadoras da Reforma Agrária [ENERA] - evento em que se começava a materializar as ideias progressistas que mais adiante resultou na criação do Setor de Educação na estrutura organizacional do MST, que, mesmo tendo todo o sistema educacional contra, alimentava o desiderato de uma "nova escola". Em síntese, a aprovação das referidas diretrizes representa a conquista da cidadania no meio rural por meio da luta e a luta traduzida em lei, resgatando o campo como lugar de desenvolvimento, como “... lugar de vida, onde as pessoas podem morar, trabalhar, estudar com dignidade de quem tem o seu lugar, a sua identidade cultural" (Arroyo, Caldart \& Molina, 2004, p. 137).

E por último, o texto que finaliza a retrospectiva histórica do Movimento "Por uma Educação do Campo" é chamado de Por Uma Educação do Campo: traços de uma identidade em construção, escrito por Roseli Caldart a partir de sua exposição no Seminário Nacional Por uma Educação do Campo, realizado em Brasília no período de 26 a 29 de novembro de 2002. E como o próprio título sugere, propõe reflexões sobre a identidade dos protagonistas do movimento e daqueles que pretendem disseminar seu ideário.

Em resumo, o texto destaca que

na sua origem, o ‘do’ da Educação do Campo tem a ver com esse protagonismo: não é 'para' e nem mesmo 'com': é dos trabalhadores, Educação do Campo, dos camponeses, pedagogia do oprimido... Um 'do' que não é dado, mas que precisa ser construído pelo processo de formação dos sujeitos coletivos, sujeitos que lutam para tomar parte da dinâmica social, para se constituir como sujeitos políticos, capazes de influir na agenda política da sociedade. (Caldart, 2009, p. 41).

Partindo do pressuposto, foi justamente por melhores condições e qualidade de vida nos acampamentos e assentamentos do MST que a luta pelo direito à educação se juntou à luta pela terra, no começo sem muita relação. 
Todavia, desde o princípio da luta social, os trabalhadores(as) do campo já carregavam em si a certeza de que uma transformação mais profunda se daria por meio da educação, conforme sublinha Caldart (2000), mas a instauração e consolidação de um modelo educativo dinâmico, que esteja voltado à formação para a autonomia, para a plenitude, para a formação de sujeitos qualificados à construção de novos paradigmas de educação e desenvolvimento, com mudanças educativas e sociais efetivas e duradouras, que inclua e considere o homem e a mulher do campo e suas utopias.

Passados dez anos da inauguração do Assentamento "Lulão", localizado no Sul da Bahia, procuramos desenvolver uma pesquisa no intuito de investigar e compreender de que modo os indicadores de desenvolvimento refletem o grau de autonomia de seus moradores, e qual o papel da educação no processo de formação de sujeitos autônomos.

A pesquisa revela que, em relação ao acesso a educação formal no assentamento, majoritariamente, mulheres $(100 \%)$ e homens $(93,33 \%)$ pesquisados/as afirmam terem este direito garantido, com igualdade de oportunidade a todos que desejam estudar, bem como respeitando as especificidades dos homens e mulheres do campo.

Já em questões relacionadas aos processos de luta social como estratégias de formação do sujeito, $100 \%$ das mulheres e $80 \%$ dos homens pesquisados atestam que a luta pela terra, pelo trabalho e por condições de uma vida digna tem relação com a sua educação e a dos seus filhos. Também, 93,33\% das mulheres e $80 \%$ dos sujeitos pesquisados reconhecem que a participação do movimento tem influência positiva no modo como eles e seus filhos aprendem e vivem dentro e fora do Assentamento, comprovando que há uma pedagogia dentro e fora da escola, circunscrita na luta, no movimento.

Tanto nos dados quantitativos trazidos na pesquisa, quanto nos qualitativos representados nas falas dos sujeitos, evidencia-se a importância atribuída à educação para o desenvolvimento sócio-econômico-cultural e ambiental do assentamento, dando grande destaque ao MST como promotor da expansão das liberdades e capacidades do indivíduo, formando-o para o exercício da cidadania. Os resultados reforçam as palavras de Cury (2002, p. 260), quando declara que

o acesso à educação é também um meio de abertura que dá ao indivíduo

\begin{tabular}{|l|l|l|l|l|l|l|l|}
\hline Rev. Bras. Educ. Camp. & Tocantinópolis & v. 3 & n. 2 & p. 381-410 & mai./ago. & 2018 & ISSN: 2525-4863 \\
\hline
\end{tabular} 
uma chave de autoconstrução e de se reconhecer como capaz de opções. O direito à educação, nesta medida, é uma oportunidade de crescimento cidadão, um caminho de opções diferenciadas e uma chave de crescente estima de si.

Nesta percepção de formação para autonomia, Caldart (2009, p. 5) também destaca que "Os Sem Terra se educam, quer dizer, se humanizam e se formam como sujeitos sociais no próprio movimento da luta que diretamente desencadeiam". A afirmação da autora corrobora a narrativa de Areca, quando define a educação como instrumento que potencializa a luta, e o conhecimento como um bem inviolável de homens e mulheres.

A educação é a base de tudo né, então assim se você não tem educação ... não consegue até mesmo lutar né, porque se você não tiver educação, você não tem a capacidade de ir pra luta né, então, o conhecimento né, esse conhecimento vem através da educação... não ter dinheiro é uma coisa, agora você enquanto pessoa, você tem os seus direitos né, você tem o direito a estudar, é através do estudo que você vai ter uma vida mais digna né, porque o conhecimento é algo que ninguém tira de você, não é? então é isso que você leva pra sua vida, e o Movimento Sem Terra esclarece muito bem isso, é dizer: oh, você tem direitos né, você é dono do seu próprio destino, não é os outros que vai fazer o seu destino, e sim você mesmo (Areca, excerto extraído do Grupo Focal $\mathrm{n}^{\circ}$ 01, realizado em maio de 2016).
Areca também nos chama atenção ao papel do MST frente à construção da autonomia dos sujeitos, especialmente ao declarar que, cada um é dono do seu próprio destino, contudo, apreendendo o que tem de direito e lutando por ele. Desse modo, como destaca Freire (1983, p. 32), a autonomia é uma conquista, e implica em libertação das estruturas opressoras. "A libertação a que não chegarão pelo acaso, mas pela práxis de sua busca; pelo conhecimento e reconhecimento da necessidade de lutar por ela".

Outro relato que merece destaque, dentre outras, é o de Aricuri, relembrando umas das místicas do movimento, "o assentamento é a nossa escola e o MST é o nosso principal educador", vê-se nessa frase que educar não é somente o papel da instituição escolar, mas o território, o movimento, a casa, a terra, que vão se configurando numa grande escola, e vão tecendo currículos que não estão preocupados apenas com o seguimento escolar, mas com a vida, o trabalho e a luta, dentre outros elementos. Ainda em relação à frase supracitada, Aricuri diz que

ela acaba ajudando a todos nessa parte da educação, porque em primeiro lugar, primeiramente em tudo, pra gente buscar tudo, a gente precisa ter a educação, não é a educação que ocorre em quatro paredes, que é uma escola ali que vai

\begin{tabular}{|l|l|l|l|l|l|l|l|}
\hline Rev. Bras. Educ. Camp. & Tocantinópolis & v. 3 & n. 2 & p. 381-410 & mai./ago. & 2018 & ISSN: 2525-4863 \\
\hline
\end{tabular} 
formar, e sim aquela educação que está presente no buscar, no agir, é aquela educação diferenciada que você precisa compreender que não é só em quatro paredes que você vai obter essa educação, é nessa conversa que a gente ta tendo aqui, que a gente vai direcionar, que a gente vai buscar esse passo a passo, não precisa a gente está nessa visão da escola de quatro paredes, mas debaixo de um pé de árvore, em uma palestra que a gente tem ali... na busca pela educação, o movimento ele se preocupa muito, em primeira instância ele se preocupa em montar num acampamento, o segundo objetivo dele é a escola, ali junto com a saúde ... ele procura buscar cada dia mais cursos: às vezes a gente vai está em uma reunião, em uma assembleia, por exemplo, ali nós achamos que só é uma discussão que está no assentamento, muitos não conseguem compreender que aquela assembleia tá sendo uma escola, porque aquela assembleia ali, ela tá direcionando, então isso que é interessante, que a cada dia me passa a cativar mais pelo movimento, porque você sem perceber acaba, a cada instante, aprendendo, como diz, somos eternos aprendizes né, a cada momento a gente tá ali buscando ... (Aricuri, excerto extraído do Grupo Focal nº4, realizado em maio de 2015).

Evidencia-se neste discurso a relevância da educação não formal dentro do MST, uma educação para além dos muros da escola; uma educação que se dá na práxis da vida cotidiana, no exercício da cidadania e na participação social; uma educação que se oportuniza na luta por direitos, no enfrentamento às estruturas de poder e opressão; o que Kant (1996, p. 30) bem defende quando diz que a educação não deve ser puramente mecânica e nem se fundar no raciocínio puro, mas deve apoiar-se em princípios e guiar-se pela experiência, por aquilo que nos toca, como bem traduz Aricuri: uma aprendizagem infinita com os pares, nas reuniões, nas assembleias, nas conversas, nas ocupações, nos conflitos, na luta.

Formar para a autonomia, tornar consciente e reflexivo este processo de aprendizagem que se dá na trajetória de luta, é, para Caldart (2009), um dos grandes desafios pedagógicos do MST e uma das principais razões de se valorizar cada vez as estratégias e práticas pedagógicas desencadeadas no interior dos assentamentos e acampamentos do movimento.

Neste sentido, somente nos assumindo como seres sócio-históricoculturais, como recomenda Freire (2007), nos reconhecendo como sujeitos de ação e ressignificação na/da história, poderemos avançar nesta expansão de capacidades e liberdades fundamentais, neste estado de consciência crítica e reflexão a que chamamos de autonomia. Sem isto, conforme Caldart (2009, p. 6), “os novos sujeitos sociais não conseguirão se tornar sujeitos políticos, capazes de efetivamente fazer diferença no desenrolar da luta de

\begin{tabular}{|l|l|l|l|l|l|l|l|}
\hline Rev. Bras. Educ. Camp. & Tocantinópolis & v. 3 & n. 2 & p. 381-410 & mai./ago. & 2018 & ISSN: 2525-4863 \\
\hline
\end{tabular} 
classes, e na reconstrução de nosso projeto de humanidade".

$\mathrm{Na}$ visão da autora, os sem-terra se educam, se formam, se libertam e, enfim, se humanizam como sujeitos sociais na medida em que participam do próprio movimento da luta pela terra e por direitos, ou seja, como já dizia Freire "a libertação a que não chegarão pelo acaso, mas pela práxis de sua busca; pelo conhecimento e reconhecimento da necessidade de lutar por ela”. (Freire, 1983, p.32).

Os relatos dos sujeitos dessa pesquisa evidenciam, a todo o momento, o quão educativo é a vivência dos processos de luta pela terra e manutenção e desenvolvimento das áreas de assentamento. A escola se configura como mais uma ferramenta de formação para autonomia dos sujeitos que ali vivem, dentre tantas outras que se desenvolvem na dinâmica da vida em comunidade. A educação, seja formal ou não, tem especial relevância e influência no desenvolvimento sócio-econômico-cultural e ambiental do Assentamento, destacando-se o princípio educativo do próprio MST, como agente promotor da expansão das liberdades e capacidades dos sem-terra, formando-os para a autonomia e para o exercício da cidadania.

\section{Desenvolvimento Comunitário Rural: um desenvolvimento medido a partir da autonomia, participação e liberdades dos sujeitos}

Segundo Silva e Arns (2002), a ideia de desenvolvimento comunitário como uma ação governamental surgiu no pósguerra, período da história em que se deu a divisão do mundo nos blocos de capitalistas e socialistas. Conforme os autores, surgiu também no início da guerra-fria, como uma estratégia dos países capitalistas para assegurar a ordem social. A ação prática proposta para o desenvolvimento comunitário, ainda segundo os referidos autores, fundamentou-se na ideia de que "a pobreza tornava os povos receptivos à propaganda comunista e de que a ajuda aos povos subdesenvolvidos reverteria em benefícios econômicos aos Estados Unidos" (Silva \& Arns, 2002, p. 6).

Foi somente a partir dos anos 50 que a Organização das Nações Unidas [ONU] se empenhou em divulgar mais sistematicamente o desenvolvimento comunitário como um

processo através do qual cada povo participa do planejamento e da realização de programas que se destinam a elevar o padrão de suas vidas. Isso implica na colaboração indispensável entre os governos e o povo para tornar eficazes os

\begin{tabular}{|l|l|l|l|l|l|l|l|}
\hline Rev. Bras. Educ. Camp. & Tocantinópolis & v. 3 & n. 2 & p. 381-410 & mai./ago. & 2018 & ISSN: 2525-4863 \\
\hline
\end{tabular} 
esquemas de desenvolvimento viáveis e equilibrados (Ammann, 1981, p. 148).

Silva e Arns (2002, p. 6) ainda revelam que o conceito de desenvolvimento começou a ganhar destaque no Brasil a partir da década de 40, com os primeiros projetos voltados ao “incremento da produção de alimentos e a educação rural e industrial", e com a criação de algumas instituições governamentais, com destaque para a Associação de Crédito e Assistência Social [ACAR], em 1948, e as Campanhas de Educação Rural [CNER] e o Serviço Social Rural, nas décadas de 40 e 50.

Já no início da década de 60, ainda conforme os autores, a prática do desenvolvimento comunitário avançou, notadamente com o fortalecimento do Movimento de Educação de Base [MEB], originado da Igreja de Natal (RN), órgão do Estado responsável por ministrar a educação nas comunidades e organizá-las socialmente.

A partir de 1964, com as mudanças no rumo político do país, em virtude do golpe militar, que reprimiu os movimentos sociais, é que o desenvolvimento comunitário seguiu outros caminhos, "passando ao contexto de 'integração social' que via a participação popular como meio de 'ajustar, cooptar, colaborar' com as diretrizes traçadas pelo Estado em programas que passaram a privilegiar os aspectos quantitativos do desenvolvimento". (Silva \& Arns, 2002, p. 6)

Foi a partir de então, de acordo com o II Plano Nacional de Desenvolvimento, que o desenvolvimento comunitário passou a ser visto como um "processo pelo qual os responsáveis locais são induzidos, por equipe técnica, a escolherem alternativas de desenvolvimento mutuamente coerentes e que se integrem nas diretrizes emanadas das instâncias superiores do governo" (Silva \& Arns, 2002, p. 6).

Como retratam os autores, o processo de mudança nos objetivos do desenvolvimento comunitário, dando aos seus programas nova orientação política, não se deu, entretanto, de forma pacífica. Ocorreram muitos conflitos nesta transição, principalmente devido ao fato do Serviço Social Rural não ter aceitado muito bem esta reestruturação do desenvolvimento comunitário em bases diferentes daquelas preconizadas pelo órgão, o qual concebia o desenvolvimento comunitário como uma pedagogia de participação. Diferentemente, o que predominou foi "uma concepção prática de participação e articulação que tinha como

\begin{tabular}{|l|l|l|l|l|l|l|l|}
\hline Rev. Bras. Educ. Camp. & Tocantinópolis & v. 3 & n. 2 & p. 381-410 & mai./ago. & 2018 & ISSN: 2525-4863 \\
\hline
\end{tabular} 
objetivo resultados estabelecidos que deixavam de fora questões estruturais do desenvolvimento" (Silva \& Arns, 2002, p. 7).

Mais adiante, na década de 1970, segundo os mesmos autores, foi que os programas de desenvolvimento comunitário foram substituídos pelo Programa Nacional de Centros Sociais Urbanos, "consolidando sua estratégia de transformar as ações de comunidades em atividades comunitárias de integração social como lazer, treinamento profissional, previdência e assistência jurídica" (Silva \& Arns, 2002, p.7).

Seguindo esta trajetória, continuam os autores, foi que a noção de desenvolvimento comunitário ficou carregada de preconceitos, uma vez que este passou a ser entendido como encobridor de "diferenças de classe e das desigualdades sociais" (Silva \& Arns, 2002, p.7). Em resumo, o desenvolvimento comunitário foi considerado pelo governo da época como uma "estratégia governamental de cooptação e desarticulação nos movimentos sociais. Já o serviço social passou a ser compreendido como conjunto de práticas assistencialistas, de caráter paliativo com o objetivo de encobrir as questões estruturais da dinâmica social". (Silva \& Arns, 2002, p. 7).

Por isso, pela trajetória equivocada do desenvolvimento comunitário, particularmente no meio rural, é que, para resolver as desigualdades sociais existentes neste meio, sobretudo erradicar o problema da pobreza, o desenvolvimento rural deve ser uma prioridade, segundo Weigand Junior et al. (2003, p. 8-9). Na visão dos autores,
A experiência nacional e internacional dos organismos de promoção do desenvolvimento em áreas rurais tem mostrado apenas insucessos e sucessos limitados. Apesar de mais de 50 anos de ações de organismos internacionais de promoção do desenvolvimento em áreas rurais, o número de pobres rurais ainda cresce, e a proporção de pobres nas áreas rurais é maior que nas áreas urbanas. A diferença de renda entre populações rurais e urbanas é agravada ainda pela falta de oportunidades e de acesso a educação e saúde.

Todavia, ainda de acordo com os autores, apesar de todas as dificuldades enfrentadas na tentativa de promoção do desenvolvimento comunitário rural, com seus sucessos e insucessos, as estratégias adotadas no sentido de promover $\mathrm{o}$ desenvolvimento em territórios fragilizados "têm mostrado que a participação das populações locais no diagnóstico dos problemas, e no 
planejamento e implementação de soluções torna as políticas e programas de desenvolvimento mais eficazes" (Weigand Junior et al., 2003, p. 9). Segundo os autores, "programas de desenvolvimento em que as populações locais participam encontram melhor aceitação, utilizam melhor os recursos locais e lidam mais frequentemente com os problemas mais importantes para as populações locais" (p. 9). Nesta perspectiva, Silva e Arns (2002, p. 8), utilizando-se da metáfora do "casulo", definem o desenvolvimento comunitário como

... o processo através do qual a comunidade amadurece em relação a si mesma e a seus potenciais, rompe seus casulos e se transforma em novas possibilidades de ser. A comunidade pré-existe ao técnico ou ao programa. Para o bem e para o mal, sua história, sua trajetória, seus significados, nos precedem, configurando cada uma delas como ser único.

Neste contexto de transformação, os autores destacam que, assim como a borboleta rompe seu casulo e alça voo, da mesma forma a comunidade tem a capacidade de amadurecer, de definir e controlar suas próprias prioridades para a mudança rumo a um modelo de desenvolvimento real, sustentável, justo e igualitário.
O sentido de comunidade a que nos referimos, trata-se de "uma relação social quando e na medida em que a atitude na ação social repousa no sentimento subjetivo dos participantes de pertencer (afetiva ou tradicionalmente) ao mesmo grupo" (Weber, 1972, p. 25). Segundo Bauman (2003, p. 15-16), “é um sentimento recíproco e vinculante - a vontade real e própria daqueles que se unem; e é graças a esse entendimento e somente a esse entendimento, que na comunidade as pessoas permanecem essencialmente unidas a despeito de todos os fatores que as separam". Essa ideia é corroborada por Areca:

\begin{abstract}
Não é que o líder vai interferir assim no que a comunidade quer fazer, não é uma interferência, há sim uma orientação, agora você pode, a sua vida é a sua vida, se nós buscamos pela independência, né, (++) ... agora depende também do que você vai atrapalhar ... (Areca, excerto extraído do Grupo Focal $n^{\circ}$ 01, realizado em maio de 2016, p. 9-10).
\end{abstract}

Ainda conforme Bauman (2003, p. 19), este tipo de comunidade, constituída a partir de um pacto social, como o que caracteriza as áreas de assentamento, “nunca será imune à reflexão, contestação e discussão" permanentes. Vimos, na pesquisa, que esse pacto social é selado entre assentados e lideranças, na forma de regimento, após ampla discussão em 
assembleia, como destacado nos relatos abaixo:

... porque aqui tem tipo um papel, o que deve e o que não pode, tipo assim, um documento de regimento falando tudo o que pode e não pode, aí você entra nas normas daquele documento e faz só o certo, porque se você sai fora da norma, você tá desrespeitando a nossa coordenação (Macaúba, excerto extraído do Grupo Focal $\mathrm{n}^{\circ} 02$, realizado em maio de 2016, p. 8).

Em assembleia (++) tem algumas coisas que tem atas registradas que tudo que não pode aqui, por exemplo, quem mora aqui, pegar sua casa e alugar pra outra pessoa que vem de fora, que a gente nem conhece, aí não pode, porque vai trazer um monte de problema pra gente, trazer filhos com problemas com drogas, com roubo, com uma série de coisas, aí a gente não aceita (Guariroba, excerto extraído do Grupo Focal $\mathrm{n}^{\circ}$ 01, realizado em maio de 2016, p. 10).

Bauman (2003) também afirma que a comunidade de entendimento comum, mesmo que alcançada, permanecerá sempre frágil, suscetível e vulnerável, exigindo a constância de forças atuantes no sentido de vigiar, reforçar e defender sua ordem e organicidade.

Ademais, com base nos dados e informações coletados no Assentamento "Lulão", constatamos que no Assentamento existe uma clara diferenciação entre os objetivos das produções individual e coletiva dentro da área, sem, contudo, ser atribuído qualquer grau de superioridade a um ou a outro, apenas de função. Enquanto a primeira produção está relacionada à composição da renda pessoal e familiar, necessária ao provento das necessidades da família e à busca por uma melhor qualidade de vida, a segunda tem uma função mais social, formativa, voltada à manutenção da cultura do associativismo.

Percebemos, ainda, que existe uma grande defesa dos processos coletivos de produção e de articulação, e mobilização social na reivindicação por políticas públicas, destacando-se a importância da união para a comunidade, a qual é atribuída à maioria dos indicadores de desenvolvimento percebidos: escola, posto de saúde, agroindústria etc. Assim, se tomarmos a oferta de serviços públicos na localidade, como indicador de desenvolvimento local, podemos inferir que o Assentamento "Lulão" é desenvolvido, se comparado a outros assentamentos rurais da região, corroborando o desiderato da comunidade, em torná-lo em referência.

\section{Considerações finais}

Neste artigo, partimos do pressuposto de que não se pode alcançar o desenvolvimento à custa da privação do

\begin{tabular}{|l|l|l|l|l|l|l|l|}
\hline Rev. Bras. Educ. Camp. & Tocantinópolis & v. 3 & n. 2 & p. 381-410 & mai./ago. & 2018 & ISSN: 2525-4863 \\
\hline
\end{tabular} 
outro, mas a partir do reconhecimento de que o desenvolvimento é influenciado positivamente pelo acesso às oportunidades econômicas, liberdades políticas, poderes sociais e por condições habilitadoras, a exemplo da educação e da participação social.

Defendemos que é através de uma participação consciente, decisória e integrada de amplos contingentes da população local, que é possível aproveitar o saber-fazer tradicional, o conhecimento detalhado da realidade e a vontade de agir dos atores sociais. No que diz respeito à educação, nossa defesa aqui, para além desta como um direito humano que deve ser emergencialmente efetivado, é que não é mais possível conceber e aceitar o desenvolvimento sem pensá-lo atrelado à ideia de promoção da autonomia dos sujeitos e à ampliação de suas capacidades e liberdades fundamentais; sem dar-lhes condições para a conquista do poder como o conhecimento que possibilita a percepção crítica da realidade e a reação frente às injustiças e desigualdades sociais; sem destacar a diversidade cultural e o respeito à diferença como importantes medidas de avaliação no processo desenvolvimentista; sem possibilitar que as populações historicamente excluídas consigam se descobrir e se assumir como capazes de traçarem suas trajetórias de desenvolvimento.

Em linhas gerais, seja no sentido da autonomia para os sujeitos, seja na dimensão social desta, constatamos que os indicadores de desenvolvimento do Assentamento Lulão têm relação direta com o elevado grau de autonomia de seus moradores. Uma autonomia forjada no próprio espaço de vivência, construída na práxis da luta por direitos e por uma vida digna, utilizada a favor da coletividade, da vida comum.

Por fim, fica clara neste artigo a intenção de ressoar a voz dos companheiros coautores deste trabalho, repercutindo o desejo de um grupo que brada um pedido de respeito a uma população historicamente subjugada. Um discurso a favor dessa educação que denuncia, de forma contundente, as heteronomias do sistema, e que nos encoraja, homens e mulheres que vivenciam a ética universal do ser humano, a nos unirmos a este movimento social e político, a promovermos e reivindicarmos essa educação que liberta e transforma.

\section{Referências}

Adorno, T. W. (1984). Negative Dialektik. In Adorno, T. W. (Org.). Gesammelte 
Schriften (pp. 7-412). Frankfurt am Main: Suhrkamp.

Ammann, S. B. (1981). Ideologia do Desenvolvimento Comunitário no Brasil. São Paulo, SP: Cortez.

Arroyo, M. G. (2004). A Educação Básica e o Movimento Social do Campo. In Arroyo, M. G., Caldart, R. S., \& Molina, M. C. (Orgs.). Por uma Educação do Campo (pp. 65-86). Petrópolis, RJ: Vozes.

Arroyo, M. G., Caldart, R. S., \& Molina, M. C. (2004). (Orgs.). Por uma Educação do Campo. Petrópolis, RJ: Vozes.

Batista, M. S. X. (2011) (Org.). Movimentos sociais, estado e políticas públicas de Educação do Campo: pesquisa e práticas pedagógicas. João Pessoa, PB: UFPB.

Bauman, Z. (2003). Comunidade - a busca por segurança no mundo atual. Rio de Janeiro, RJ: Jorge Zahar Ed.

Bobbio, N. (2000). O Futuro $d a$ democracia. São Paulo, SP: Brasiliense.

Brasil. (2005). Discurso do Presidente da República, Luiz Inácio Lula da Silva, na visita ao Assentamento Lulão. Recuperado de

http://www.biblioteca.presidencia.gov.br/p residencia/ex-presidentes/luiz-inacio-lulada-silva/discursos/1o-mandato/2005/2809-2005-discurso-do-presidente-darepublica-luiz-inacio-lula-da-silva-navisita-ao-assentamento-201clulao201d

Caldart, R. S. (2000). Pedagogia do Movimento Sem-Terra. Petrópolis, RJ: Vozes, 2000.

Caldart, R. S. (2009). Educação do Campo: notas para uma análise de percurso. Trab. educ. saúde, 7(1), 35-64. DOI:
http://dx.doi.org/10.1590/S1981$\underline{77462009000100003}$

Castoriadis, C. (1991). A Instituição imaginária da sociedade. Rio de Janeiro, RJ: Paz e Terra.

Chauí, M. S. (1990). Cultura e Democracia: o discurso competente $e$ outras falas. São Paulo, SP: Cortez Editora.

Cury, C. R. J. (2002). Direito à educação: direito à igualdade, direito à diferença. Cadernos de pesquisa, 116, 245-262. DOI: http://dx.doi.org/10.1590/S0100$\underline{15742002000200010}$

Favareto, A. S. (2006). Paradigmas do desenvolvimento rural em questão - do agrário ao territorial. São Paulo, SP: USP.

Freire, P. (1983). Pedagogia do Oprimido. Rio de Janeiro, RJ: Paz e Terra.

Freire, P. (2007). Pedagogia da autonomia - saberes necessários à prática educativa. Rio de Janeiro, RJ: Paz e Terra.

Freire, P., \& Shor, I. (1986). Medo e ousadia: o cotidiano do professor. Rio de Janeiro, RJ: Paz e Terra.

Frey, K. (2000). Políticas públicas: um debate conceitual e reflexões referentes à prática da análise de políticas públicas no Brasil. Planejamento e Políticas Públicas, 21, 211-259. Recuperado de http://www.ipea.gov.br/ppp/index.php/PPP /article/viewFile/89/158

Kant, I. (1974). Fundamentação da metafísica dos costumes. In Civita, V. (Org.). Os pensadores. São Paulo, SP: Abril Cultural.

Kant, I. (1996). Crítica da Razão Pura. Trad. Valério Rohden e Udo Valdur 
Moosburger. São Paulo, SP: Nova Cultural.

Morin, E. (2002). A cabeça bem - feita. Rio de Janeiro, RJ: Bertrand Brasil.

Pereira, M. R. (2007). A inclusão da autonomia como indicador de desenvolvimento humano diante da formação da social brasileira. Jornada Internacional de Políticas Públicas (JOINPP). In III Jornada Internacional de Políticas Públicas. São Luís, MA, 28 a 30 de agosto 2007.

Rousseau, J. J. (1978). Do contrato social. São Paulo, SP: Abril Cultural.

Sachs, W. (editor). (2000). Dicionário do Desenvolvimento: guia para o conhecimento como poder. Petrópolis, RJ: Vozes.

Santos, J. (2015). Agroecologia na Escola Municipal Paulo Freire Santa Cruz Cabrália BA: estudo da relação comunidade escola. São Paulo: USP.

Sen, A. K. (2008). Desenvolvimento como liberdade. São Paulo, SP: Companhia das Letras.

Silva, M. T. R., \& Arns, P. C. (2002). Desenvolvimento

Empreende. Projeto BNDES Desenvolvimento Local - Cooperação Técnica do Programa das Nações Unidas para o Desenvolvimento (PNUD). Recuperado de http://docplayer.com.br/8552493-Projetobndes-desenvolvimento-local-cooperacaotecnica-do-pnud-desenvolvimentocomunitario-maria-teresa-ramos-da-silvapaulo-cesar-arns.html

Veiga, J. E. (2005). Desenvolvimento Sustentável: o desafio do século XXI. Rio de Janeiro, RJ: Garamond.
Veiga, J. E. (2006). Meio Ambiente $e$ desenvolvimento. São Paulo, SP: SENAC, 2006.

Weigand Junior, R., Viana, C. F. G., Shiki, S. F. N., Duncan, M., \& Eneias, L. (2003). Experiências brasileiras de desenvolvimento territorial rural sustentável. In Fórum Internacional Território, Desenvolvimento Rural e Democracia, 1., Fortaleza, CE.

Weber, M. (1972). Economia e sociedade. Brasília, DF: UnB.

\footnotetext{
Segundo dados da Secretaria Municipal de Saúde/Unidade Básica de Saúde (2016).
}

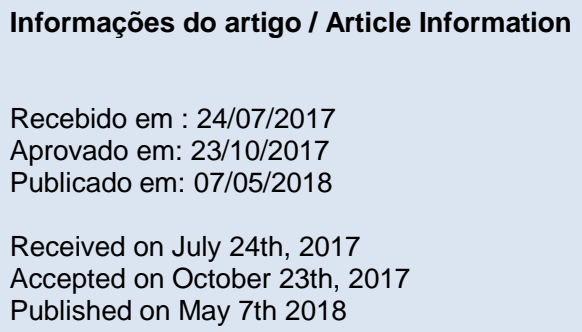

Contribuições no artigo: Os autores, conjuntamente, foram os responsáveis por todas as etapas e resultados da pesquisa, a saber: elaboração, análise e interpretação dos dados; escrita e revisão do conteúdo do manuscrito e; aprovação da versão final a ser publicada.

Author Contributions: The authors were responsible for the designing, delineating, analyzing and interpreting the data, production of the manuscript, critical revision of the content and approval of the final version to be published. 
Felberg, A., \& Silva, G. J. (2018). Educação do Campo e Autonomia: desenvolvimento comunitário e pedagogia de participação no Assentamento do Movimento Sem Terra...

Conflitos de interesse: Os autores declararam não haver nenhum conflito de interesse referente a este artigo.

Conflict of Interest: None reported.

\section{Orcid}

Altemar Felberg

(iD) http://orcid.org/0000-0001-8795-3768

Geovani de Jesus Silva

(iD) http://orcid.org/0000-0003-4180-4534

\section{Como citar este artigo / How to cite this article}

APA

Felberg, A., \& Silva, G. J. (2018). Educação do Campo e Autonomia: desenvolvimento comunitário e pedagogia de participação no Assentamento do Movimento Sem Terra. Rev. Bras. Educ. Camp., 3(2), 381-410. DOI: http://dx.doi.org/10.20873/uft.2525-4863.2018v3n2p381

\section{ABNT}

FELBERG, A.; SILVA, G. J. Educação do Campo e Autonomia: desenvolvimento comunitário e pedagogia de participação no Assentamento do Movimento Sem Terra. Rev. Bras. Educ. Camp., Tocantinópolis, v. 3, n. 2, mai./ago., p. 381-410, $2018 . \quad$ DOI: http://dx.doi.org/10.20873/uft.2525-4863.2018v3n2p381 